\title{
Glycosylation of uroplakins. Implications for bladder physiopathology
}

\author{
Iwona Kątnik-Prastowska • Jolanta Lis • Agata Matejuk
}

Received: 25 August 2014 / Revised: 10 October 2014 / Accepted: 13 October 2014 / Published online: 15 November 2014

(C) The Author(s) 2014. This article is published with open access at Springerlink.com

\begin{abstract}
Urothelium, a specialized epithelium, covers the urinary tract and act not only as a barrier separating its light from the surrounding tissues, but fulfills an important role in maintaining the homeostasis of the urothelial tract and wellbeing of the whole organism. Proper function of urothelium is dependent on the precise assemble of highly specialized glycoproteins called uroplakins, the end products and differentiation markers of the urothelial cells. Glycosylation changes in uroplakins correlate with and might reflect progressive stages of pathological conditions of the urothelium such as cancer, urinary tract infections, interstitial cystitis and others. In this review we focus on sugar components of uroplakins, their emerging role in urothelial biology and disease implications. The advances in our understanding of uroplakins changes in glycan moieties composition, structure, assembly and expression of their glycovariants could potentially lead to the development of targeted therapies and discoveries of novel urine and plasma markers for the benefit of patients with urinary tract diseases.
\end{abstract}

Keywords Uroplakins · Urothelium · Glycosylation · Glycomarkers · Urothelial pathologies

$\begin{array}{ll}\text { Abbreviations } \\ \text { Asn } & \text { asparagine } \\ \text { Gal } & \text { galactose } \\ \text { GlcNAc } & N \text {-Acetylglucosamine } \\ \text { Man } & \text { mannose } \\ \text { Fuc } & \text { fucose } \\ \text { P } & \text { phosphate }\end{array}$

I. Kątnik-Prastowska $\cdot$ J. Lis $\cdot$ A. Matejuk $(\bowtie)$ Department of Chemistry and Immunochemistry, Medical University of Wroclaw, Bujwida 44a, 50-345 Wroclaw, Poland

e-mail: agata.matejuk@umed.wroc.pl
Sia
TD
sialic acid
transmembrane domain
$1-3$
$\mathrm{N}$-glycosylation sites

\section{Introduction}

Urothelium is a multilayer epithelium of the inner surface of the mammalian urinary bladder which extends from the renal pelvis to the urethra. It is composed of three to six layers of heterogeneous epithelia cells at different stages of differentiation, that contain basal, intermediate and umbrella cells (Fig. 1a) [1-3]. Urothelium is an unusual epithelial tissue because of stratified complex of cellular layers with intimate connections to neural and connective tissue elements $[4,5]$. The mammalian urothelium apical surface is in $90 \%$ covered by urothelial plaques [6] forming the membrane interdigitation at the cell borders [7]. This interdigitation creates a membrane zipper, likely contributing to the barrier function of the urothelium $[2,7]$. The urothelial plaques or "asymmetric unit membrane" (AUM) (Fig. 1b) are constructed by uroplakins (UPs) (Fig. 1c), the markers of the advanced degree of the differentiation stage of umbrella cells [reviewed in [5, 8-11]. In mammals characterized by a thicker layer of the urothelium (e.g., humans), UPs are mostly present on the cell surface, in mammals with thinner urothelium (e.g. rodents), they can be also found in the deeper layers of the tissue [12]. UPs are highly tissue-specific, but in mice, some of their isoforms have been also identified in the mammary gland, pancreas, lung and heart [11]. Studies using transgenic models for UP and models with inactivated genes for these proteins provided important data regarding their function. Variation in their normal expression leads to a variety of urinary disorders such as vesicourethral, interstitial cystitis (IC), overactive bladder, hydronephrosis or renal dysfunction and renal failure $[6,11,13,14]$. 
Fig. 1 Scheme of the urothelium and uroplakin plaque composition. Urothelium is composed of three layers: a basal cell layer attached to a basement membrane, an intermediate layer, and an apical layer with large hexagonal cells known as umbrella cells (a). The apical surface of umbrella cells creates a unique asymmetric unit membrane (AUM) composed of hexagonal plaques with six tetramers where two dimers UPIa/II and Ib/IIIa are linked (b). High-mannose N-glycan (light gray circle) on UPIa and complex $\mathrm{N}$-glycans (dark gray circle) on UPIb and IIIa are depicted. Mature UPII lacks sugar moieties (c). Drown based on $[22,46]$
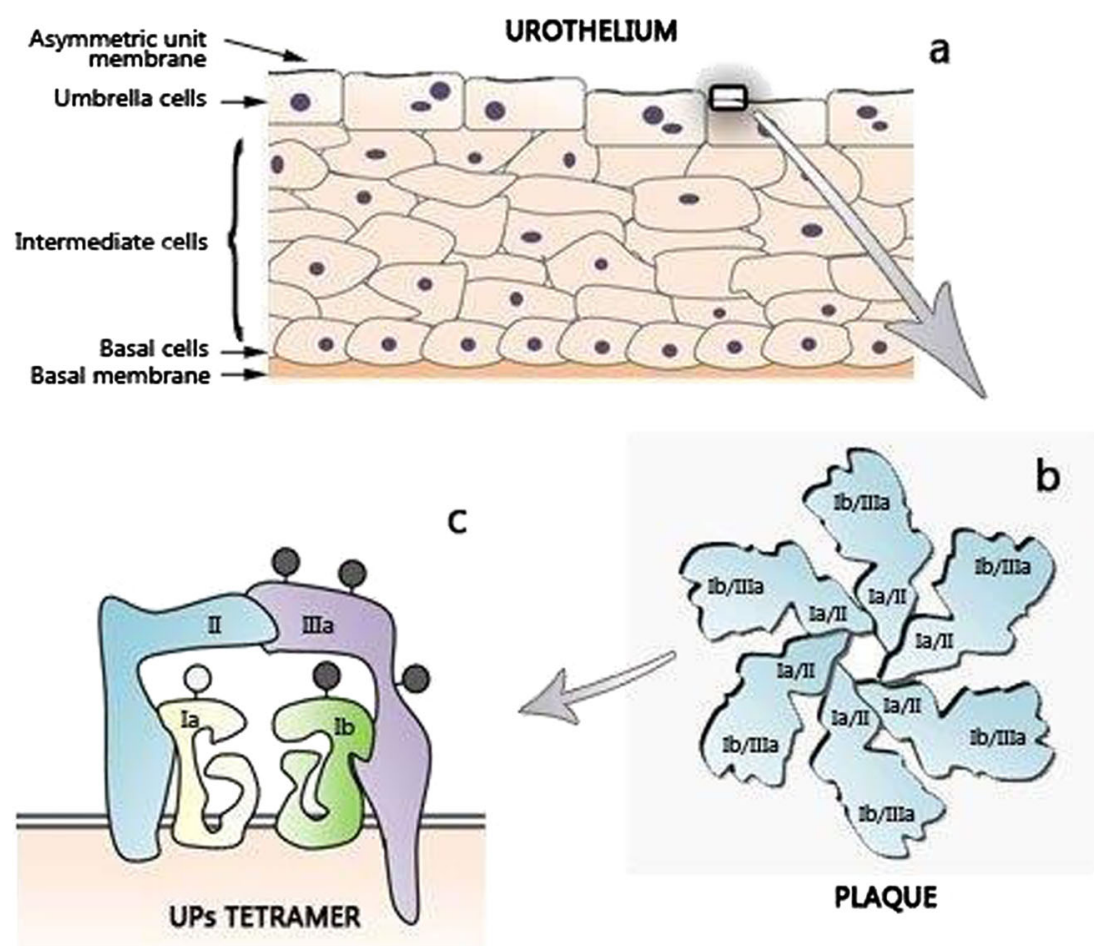

UPs, including immature form of UPII, are glycoproteins which are inextricably linked to their function. Disorders in normal glycosylation of UPs lead to abnormal epithelial adhesion, leakage of the urinary tract, increased tumor cell invasiveness and spread of Escherichia coli (E. coli) infection $[15,16]$. However, little is known and understood how qualitative and quantitative changes in their sugar structures may influence pathological conditions of the urothelium. In depth knowledge of UPs glycosylation malfunctions might find applications in early diagnosis and targeted treatments of urinary tract pathologies. Presented review brings this fascinating but yet unexplored area in urothelium research.

\section{Uroplakins are the main structural components of urothelium}

AUM of all mammalian urinary bladder comprises four major UPs: UPIa and Ib, UPII, and III, which form a unique crystalline 2D array of 16-nm particles covering almost the entire polarized urothelial surface (Fig. 1) [17]. UPI a and Ib (27$\mathrm{kDa}$ and $28-\mathrm{kDa}$, respectively) belong to the tetraspanin family. Their rod-shaped structures have four closely packed transmembrane helices (Fig. 2) spanning the membrane and extending into the extracellular loops, capped by a disulfidestabilized head domain [18, 19]. In contrast, UPII and III (15$\mathrm{kDa}$ and III $47-\mathrm{kDa}$, respectively) cross the membrane only once and their single transmembrane domain (Fig. 3) share a stretch of $\sim 12$ amino acid residues on the extracellular side [5, 8, 9, 20-22].

UPs are synthesized as monomers, however they undergo a dynamic and highly regulated assembly process, which begins in the endoplasmic reticulum (ER) where UPIa with UPII and UPIb with UPIII form specific cross-linked heterodimers [5, $8,23,24]$. Formation of the UPIa/II and UPIb/IIIa heterodimers is a prerequisite for UPs to exit ER [24]. That stage of heterodimer formation seems to be functionally important as the ablation of UPsII or III genes abolishes urothelial plaque formation and compromises their function [6, 13, 25]. However, Tu et al., [24] reported that UPIb can exit ER without a heterodimeric complex formation. In a post-Golgi compartment, UPs heterodimers form increasingly larger crystalline arrays. Two heterodimers bind to a heterotetramer through tight interactions of the transmembrane domains as well as the extracellular domains, so that the head domains of their tall partners can bridge each other at the top (Fig.1b). At turn, the interactions between the complexes and the tertiary interaction between the 16-nm particles contribute to the formation of UP tetraspanin structural/signaling networks. The aggregated UP complexes are sorted at the trans-Golgi network (TGN) into destined vesicles, which subsequently cover almost all mature fusiform vesicles in cytoplasm. These organelles migrate towards the apical cell surface where they fuse with the plasma membrane. By consequence, almost the entire apical urothelial surface is covered by $16-\mathrm{nm}$ particles of urothelial plaques composed of UPs hexagonally packed into unique paracrystalline array $[8,18,23,26,27]$. The unique 
Fig. 2 Sugar moieties on UPIa and $\mathrm{Ib}$. UPIa and $\mathrm{Ib}$ possess four transmembrane domains (TD) (shown as cylinders) containing conserved aa residues. TD1 and TD2 are connected via a small extracellular loop (EC1), and TD3 and TD4 via a large extracellular loop (EC2). The main glycovariant of UPIa contain a high-mannose glycan linked to Asn-169 (a), whereas UPIb has a tetraantennary fucosylated complex glycan linked at Asn131 (b). Abbreviations: Asn asparagine; Gal galactose; GlcNAc N-Acetylglucosamine;

Fuc fucose; Man mannose

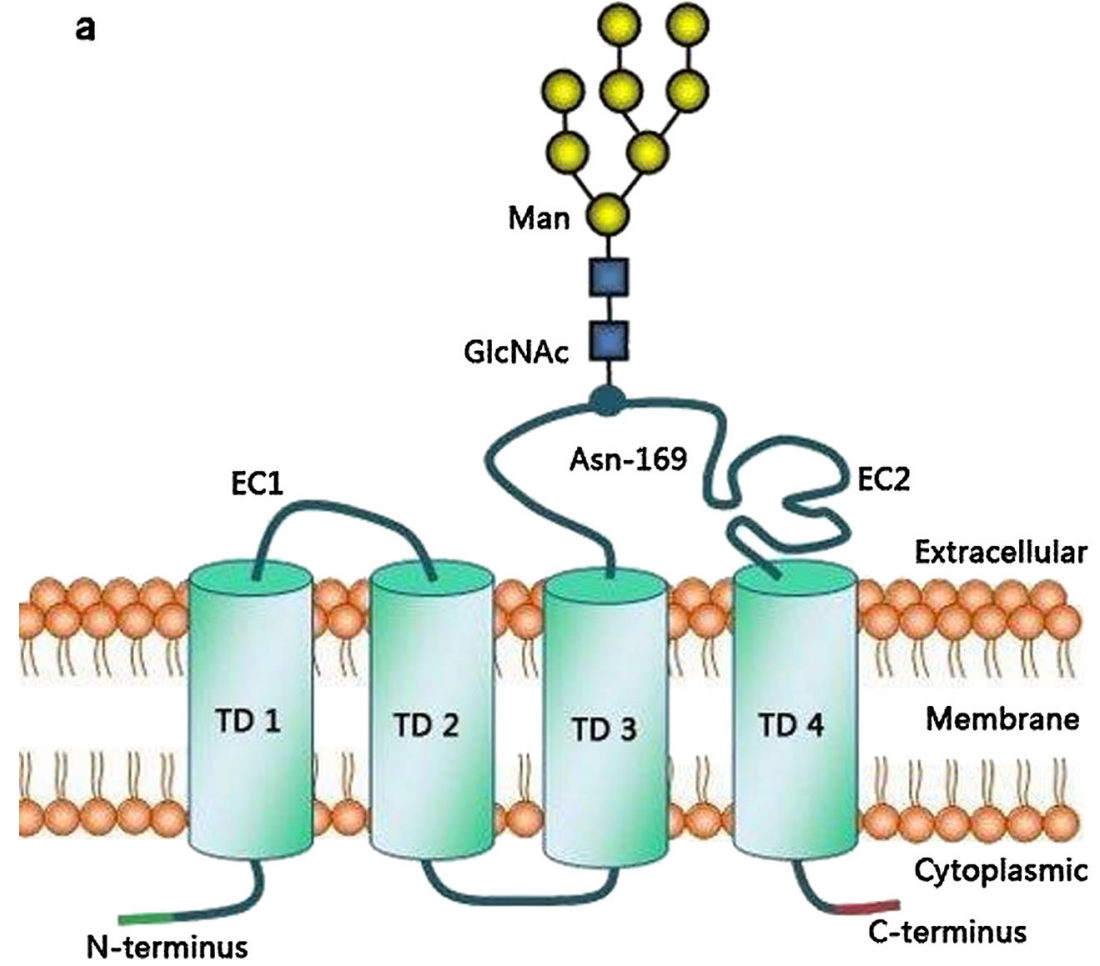

b

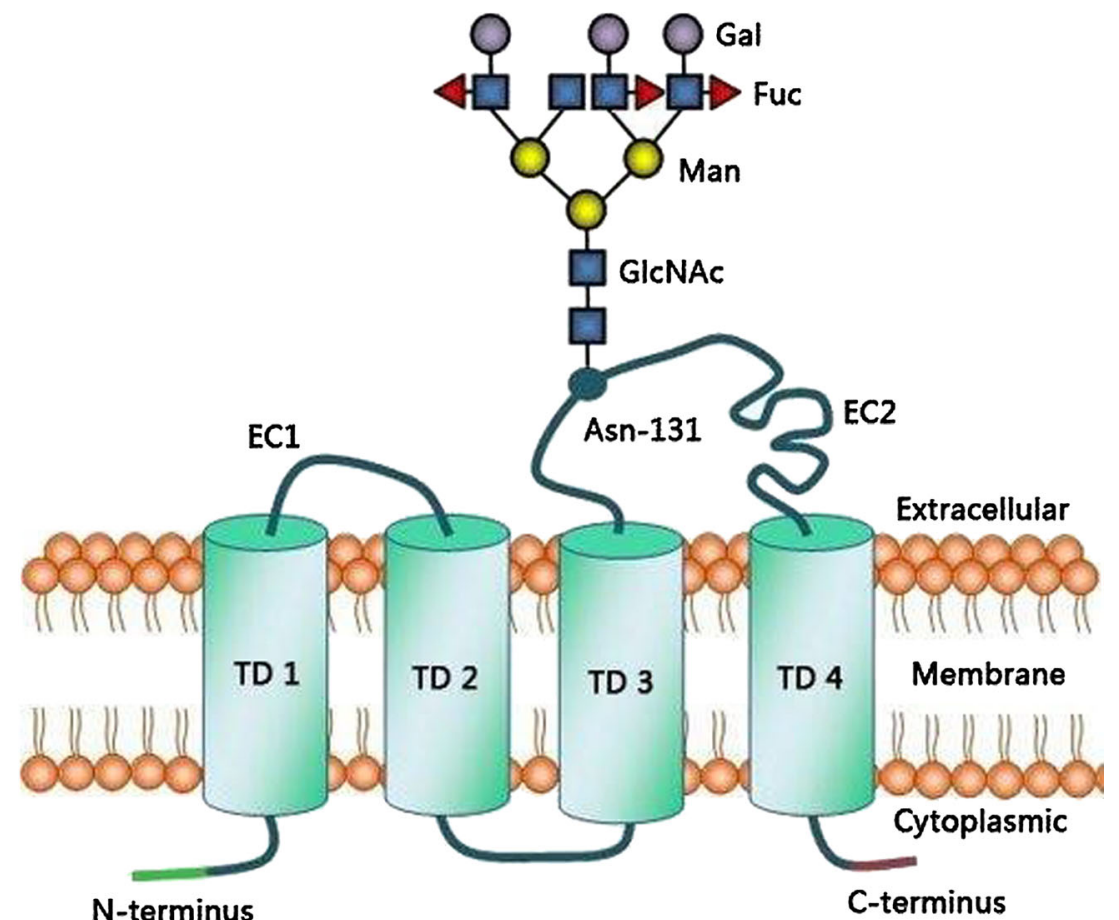

architecture of the hexagonal urothelial plaques with the distinctive cellular interconnections are critical for tightness, integrity and proper function of the urothelium $[2,5,6,11$, $28,29]$. Little is known about the molecular events governing fusiform vesicles trafficking into the luminal surface and their incorporation into apical surface. Some molecules, such as a myelin-and-lymphocyte protein (MAL) expressed by T lymphocytes, myelin-forming cells, and polarized epithelial cells 
Fig. 3 The dynamic glycosylation modifications during maturation of UPII. UPII is synthesized as a precursor prepropeptide (a). Cleavage of the signal peptide facilitates $\mathrm{N}$ glycosylation of the propeptide by high-mannose glycans (b). The synthesis of preproUPII and signal peptide cut off take place in ER. In GA two of the three highmannose N-glycans of the proUPII are transformed into complex glycans (c). Cleavage of the glycosylated propeptide UPII lacks asparagine and thus sugar moieties (e). Abbreviations: $E R$ endoplasmic reticulum; $G A$ Golgi apparatus; $T G N$ trans-Golgi network, 1-3- N-glycosylation occurs in TGN (d). The mature sites. Drown based on [22]
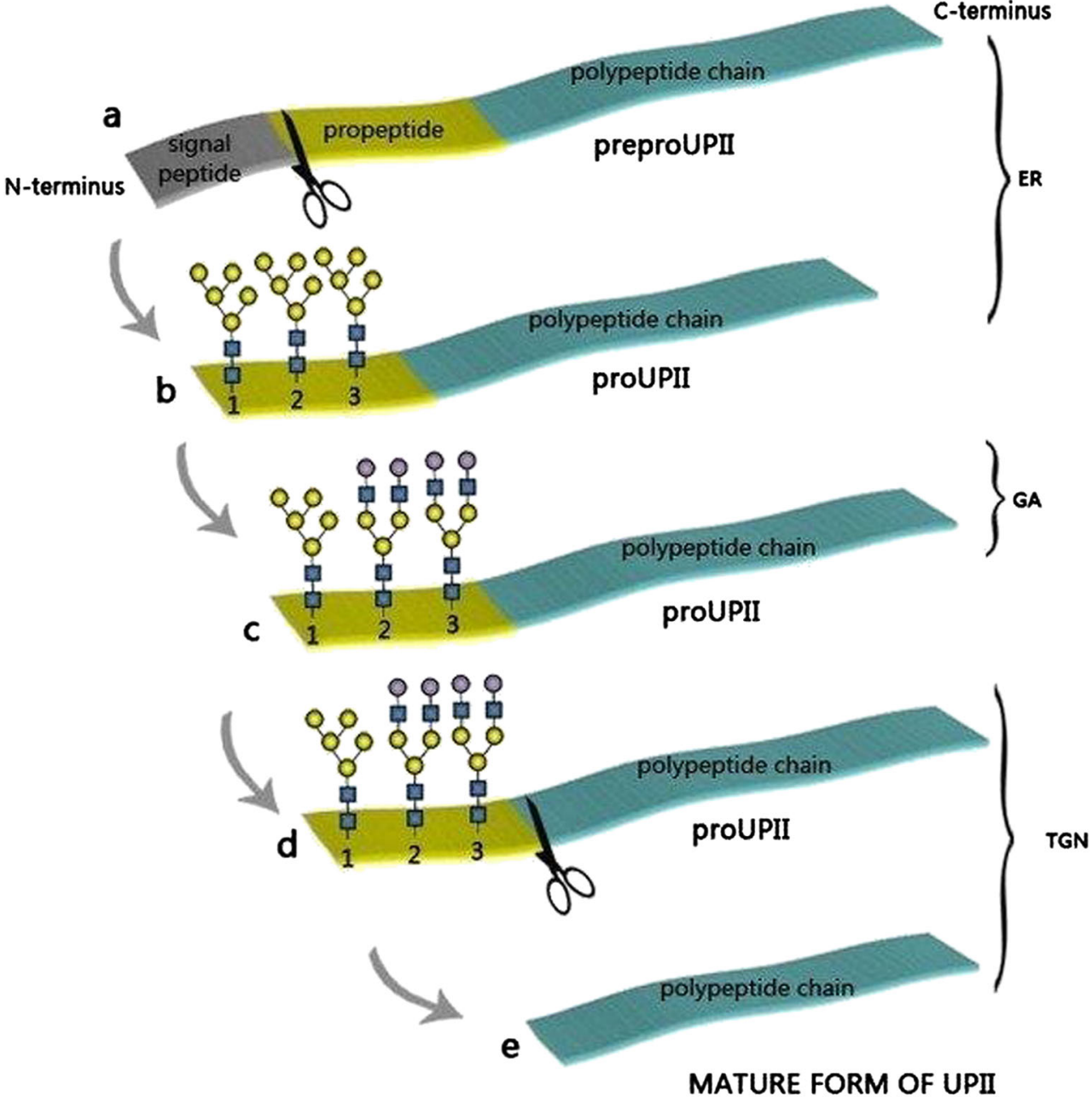

were reported to facilitate the incorporation of exocytic uroplakin-delivering vesicles into the apical membrane of urothelial umbrella cells [26, 27, 30-32].

UPs are tissue-specific molecules, but some of their isoforms have been also identified in other organs. For example in mice they have been found in the mammary gland, pancreas, lung and heart [11]. Adachi et al. [33] reported that UPIb is expressed in several non-urothelial epithelia, such as the corneal epithelium.

\section{$\mathrm{N}$-glycans of UPs, O-glycoproteins and proteoglycans form urothelial glycocalyx}

Urothelium is highly glycosylated tissue with luminal surface covered by glycocalyx composed of proteoglycans, N- and Oglycoproteins including secretory mucins. Quantitative analysis of the sialic acid, uronic acid, and hexosamine contents of delipidated rabbit bladder mucosa revealed a larger proportion of sialoglycoproteins as compared to glycosaminoglycans (GAG) [34].
The degree of glycosylation and microheterogeneity of the urothelium glycoproteins were reported to be associated and dependent on the origin of the species, the particular distribution in the multilayers of the urothelium, and the stage of the maturation and differentiation of urothelial cells. Using peanut agglutinin and Vicia villosa lectin as well as specific monoclonal antibodies, Vinter-Jensen and Ørntoft. [35] showed the presence of $\mathrm{T}$ and $\mathrm{Tn}$ antigens and mucin -type glycoproteins on murine and porcine urothelial tracts [35]. The expression of $\mathrm{T}$ and $\mathrm{Tn}$ glycotops on urothelium has been upregulated after stimulation of cell layers lining the urinary tract with epidermic growth factor (EGF) [35]. So far, certain mucins, such as MUC1 (epitectin) and proteoglycans, such as syndycan-1 have been isolated and characterized [36, 37]. As shown by Higuchi et al. [38] the rabbit mucins and glycoproteins of urothelium surface layers consisted of weakly sialylated and neutral oligosaccharides O-glycosidically linked to serine and threonine residues. In addition, the deeper layers of the rabbit urothelium (e.i., lamina propria and muscle layer) are rich in GAGs, mainly hyaluronates and chondroitin sulfates, which presence on the surface of the urothelium are 
negligible [38]. By lectin-histochemistry, Desantis et al., [39] characterized sialylated O-linked glycans expressed on donkey (Equus asinus) urothelium. These glycans contained terminal or internal mannoses, and typical secretory moieties of sialylated O-glycoproteins (sialylated galactose and disaccharide composed of galactosamine-galactose). Expression of sialic acid on glycoproteins might indicate that the urothelium is not simply a inert barrier but can modulate the composition of soluble urinary proteins, which may play pathophysiological roles in the lower urinary tract [39]. Several urotheliumderived glycoproteins have been detected in urine of cows [1], rabbits [34, 36], pigs [40], rats [35] and people [37, 40, 41]. Using glycoproteomic technique Halim et al. [41] characterized $53 \mathrm{~N}$-and $\mathrm{O}$ - glycoproteins out of 2,800 proteins present in human urine. They depicted $58 \mathrm{~N}$ - and $63 \mathrm{O}$ - glycan profiles and urine complex type glycoproteins have been found to be sialylated and fucosylated bi- and multi- branched [41].

Closely related and conservative in their structure, transmembrane UPs types $\mathrm{Ia} / \mathrm{Ib}(25-\mathrm{kDa} / 27-\mathrm{kDa})$, IIIa/IIIb (45$\mathrm{kDa} / 35-\mathrm{kDa})$ and immature form of UPII are $\mathrm{N}$ glycoproteins $[42,43]$. Their N- linked complex type oligosaccharides elicit microheterogenity. Thus, UPs can exist in several glycoforms, such as a high-mannose, bi- and/or more branched glycans, which could be further sialylated and/or fucosylated [42].

The function of urothelium glycoproteins can be related to those ascribed generally to the glycoproteins, and specific to the tissue. In the urothelium, their function is bound to the protection of membrane components from digestion by hydrolases, particularly present in the urine [40], participation in intercellular signaling, cell adhesion and recognition, selective permeability of molecules across the blood - urine barrier [1, $4,10,40,44]$ and inhibition or promoting of bacterial colonization $[42,45]$. There is some experimental evidence that unique architecture of urothelial plaques and function are strictly dependent of the UP glycosylation $[5,6,15,16,21$, 22].

\section{Glycosylation of UPIa and UPIb differs markedly}

UPIa and $\mathrm{Ib}(25$ and $27-\mathrm{kDa})$ are members of the tetraspanin family of glycoproteins with four transmembrane domains (TD 1-4) creating minor and larger loops, where the latter is stabilized by three disulfide bridges [19]. Both UPs are closely related, rich in charged amino acids approx. $40 \%$ identical [4, $22,46,47]$. Sugar parts of UPs Ia and Ib are located in the extracellular portion of their top surface (Fig. 2) exposed to the urothelium, in the hydrophilic larger loop connecting 3 and 4 TD domains [8].

In the 90s of the last century, based on data obtained by UPs N-glycosidase digestion it was assumed that both UPs: Ia and $\mathrm{Ib}$ on their extracellular surface domains carry high- mannose $\mathrm{N}$-glycans, which protect protein part from digestion by proteases [8, 46, 48]. However, in 2001 Zhou et al. [14] reported that mouse UPs Ia and $\mathrm{Ib}$, despite their identity in amino acid sequence, are glycosylated differently, and only UPIa harbors terminal mannose moieties, whereas the UPIb does not [14]. In 2006 Xie et al. [42] using more advanced techniques (permethylation of released glycans by in-gel glycosidase and protease digestion and mass spectrometric technique) confirmed that each of UPIs has only one potential Nglycosylation site. Mouse UPIa (25-kDa) possesses a glycan attached to Asn at 169 aa sequence position (Asn -169) (Fig. 2a) and UPIb (27-kDa) at 131 (Asn -131) (Fig. 2b). Murine and human UPIa are highly mannosylated with six to nine molecules of terminal mannose residues attached to $N$ acetylglucosamine core part (Man6GlcNAc2 and Man9GlcNAc2) (Fig. 2a) [42]. The predominant (43\%) murine glycovariant of UPIa contains eight terminal mannoses, whereas other glycoforms terminated by 7, 9 and 5 mannoses represent $28 \%, 24 \%$ and $5 \%$, respectively. In contrast, mouse UPIb is multi-antennary complex type oligosaccharide rich in fucoses (Fig. 2b). The fucosylated tetra-antennary $\mathrm{N}$ glycoform is the main mouse UPIb glycovariant. A highmannose variant of UPIb with 6 mannose residues and/or the hybrid type were found to be rare and constitute only $6 \%$ to $15 \%$ of UPIb [42].

The UPIa interact with the immature form of UPII (proUPII, i.e. containing a prosequence) whereas UPIb with UPIIIa forming UPIa/UPII and UPIb/UPIIIa heterodimers, respectively. That stage of dimer formation is important and facilitate their ER exit [22, 24, 49, 50]. Xie et al., [42] suggested that the drastically different carbohydrate processing of UPIa and UPIb proteins may reflect differences in their folding, masking and the interactions with associated proteins. The differences might be related to differences in accessibility of nascent proteins to glycosylation and/or alternatively to heterodimer formation. The initial step of $\mathrm{N}$-glycosylation, a co-translational process is identical for both proteins i.e., the transfer of an N-glycan precursor, Glc3Man9GlcNAc2, from lipid-linked dolichol to a protein glycosylation site. The subsequent trimming of the precursor by alpha-mannosidases in ER and addition of other sugar moieties by glycosyltransferases in the Golgi complex [51, 52] vary significantly for UPIa and UPIb depending on peptide folding and accessibility of the glycosylation sites to glycosylating enzymes [42]. On the other hand, an alternative interpretation by Xie et al. [42] is that the prosequence portion of pro-UPII upon binding to its partner UPIa in ER can block UPIa's single glycan from further trimming by the sugar-modifying enzymes.

It has been reported that mannosylated oligosaccharide part of UPIa can serve as the receptor for the FimH lectin adhesin of type 1-fimbriated $E$. coli, the bacteria that causes a great majority of urinary tract infections $[11,14,42,53]$. This topic will be discussed in chapter below. 


\section{Differentiation-dependent glycosylation of UPII}

Based on sequence analysis of cDNA/gen and mRNA translation it has been established that UPII is primarily synthesized as a $19-\mathrm{kDa}$ non-glycosylated prepro-UPII precursor (Fig. 3a). It comprises three parts of linked sequences: 1) a N-terminal 26-28 amino acids fragment (2-kDa), 2) a middle fragment located at 59 amino acids propeptide with three asparagines, the potential sites for $\mathrm{N}$-glycosylation, and 3) a 100 amino acids polypeptide $(15-\mathrm{kDa})$ corresponding to the mature native form of UPII $[8,20,48]$. The prepro-UPII precursor undergoes dynamic glycosylation modifications differentiation-dependent $[5,54]$, resulted probably from different participation of cellular glycosyltransferases [55]. In ER the signal sequence is cut-off from the $19-\mathrm{kDa}$ prepro-UPII precursor. A propeptide is further glycosylated by addition of three attached high-mannose N-glycans. The attachment of sugar chains to pro-UPII causes an increase in the molecular weight of the immature form of UPII to $29-\mathrm{kDa}$ (Fig. 3b). Further increase of molecular mass of proUPII to $32-\mathrm{kDa}$ is associated with the transformation of two out of three high-mannose glycans into complex glycans (Fig. 3c) [5, 22, 24, 54]. Next, in TGN the glycosylated peptide is cut-off from pro-UPII (Fig. 3d) and mature form of UPII is created. The precursor of bovine pro-UPII which carries complex Nglycans does not contain exposed sites susceptible for degradation by exoproteases, but has four furino-like endoproteases. For efficient cleavage, the furin-cleavage site requires some arginines in signature sequence: $\mathrm{Arg}-4-\mathrm{Xaa}-$ 3-(Lys/Arg)-2-Arg-1 [56]. The released mature bovine UPII $(15-\mathrm{kDa})$ does not possess the asparagines/s able to be Nglycosylated [20]. The mature UPII bound with a cell has a long extracellular domain of 71 amino acids, a transmembrane domain of 25 amino acids, and short intracellular domain [8, $20,48]$. It has been suggested that the furin-mediated cleavage of the glycosylated prosequence of UPII plays a role in regulating the assembly of UP to form AUM [22].

An analogous scheme for maturation of UPII was reported for UPII of nearly all mammals with the exception of mouse UPII where propeptide possesses one potential glycosylation site [48]. However, there is no data on whether mature form of mouse UPII expresses or not oligosaccharide parts.

The pro-UPII by itself cannot exit ER unless is stabilized by partner's UPIa. [22, 24]. The glycosylation alternations are responsible for conformational changes in pro-UPII that allow heterodimer formation. According to Hu et al., [22], the highmannosyl-glycans on pro-UPII appear only in ER and later, the mannosylated glycans are further processed in Golgi network. In consequence two of them become the antennary complex type oligosaccharides. Moreover, Hu et al., [57] indicated that the prosequence of UPII requires a proper disulfide linkage in order to maintain hairpin-like proUPII conformation which facilitate binding to UPIa and the formation of the proUPII/UPIa complex. It has been reported that the induced conformational changes allow UPIa/proUPII complex to exit ER and facilitate further proUPII maturation [5, 22, 24, 54]. Hu et al. [22] hypothesized that a special, complex glycan-forming glycosyltransferase in superficial umbrella cells might be involved in producing AUMassociated $32-\mathrm{kDa}$ pro-UPII, which in turn can promote the binding of two partner's heterodimers (UPIa-UPII and UPIbUPIII) to form a heterotetramer.

The exclusive expression of all high-mannose glycans on pro-UPII, and lack of the antennary complex $\mathrm{N}$-glycans, can exclude a heterotetramer formation and finally can cause a lack of AUM on the surface of umbrella cells [22]. Moreover, the high-mannose N-glycans of pro-UPII participate in preventing the crystalline plaques assembly in undifferentiated intermediate cells of urothelium [22]. Interestingly, the differentiation-dependent glycosylation of pro-UPII does not occur in cultured bovine urothelial cells, and the synthesized UPs do not assemble into crystals in cultured cells [54].

\section{UPIII comprises a large N-linked oligosaccharide moiety}

UPIII (UPIII 47 to 49-kDa) is a single, typical integral transmembrane glycoprotein with three potential $\mathrm{N}$-glycosylation sites (Fig. 4) and cysteine residues on N-terminal extracellular domain (189 amino acids). UPIII carbohydrates significantly contribute to the surface glycocalyx [9]. Charged residues of a shorter, C-terminal cytoplasmic part of UPIII (52 amino acids) have multiple potential phosphorylation sites. Deglycosylation and cDNA sequencing revealed that UPIII contains a large N-linked oligosaccharide moiety of up to $20-\mathrm{kDa}$ attached to a $28-\mathrm{kDa}$-core protein.

The composition of sugar part of UPIII is species dependent. The polypeptide part of bovine UPIII consists of 287 amino acids $(28.9-\mathrm{kDa})$, and its large sugar moiety constitute more than $40 \%$ of the total mass of the whole molecule [9, 48]. This sugar moiety is larger than glycans expressed by other uroplakins. The deglycosylation of bovine glycoprotein by specific $\mathrm{N}$-glycosidase $\mathrm{F}$ (PNGase F) and O-glycosidase digestions indicates that UPIII contains $\mathrm{N}$-linked glycan/s and lacks O-linked glycan/s [9]. Based on cDNA sequence analyses, $\mathrm{Wu}$ and Sun [9] hypothesized that UPIII sequence contains four potential N-glycosylation sites. They pointed out three N-glycosylation sites at Asn34, Asn74, and Asn170 [9]. They also suggested that the glycosylation at Asn34 is questionable because of a proline [9]. So far, there is no experimental data showing which of predicted glycosylation sites are truly glycosylated. Malagolini et al. [58] showed that N-oligosaccharides of bovine UPIII can be terminated by sialic acid $\alpha(2-3)$ - and $\alpha(2-6)$-linked to Gal(1-4)GlcNAc-sequence, however some other glycovariants may contain the terminal Gal $\alpha(1-3)-G a l$ epitope formed by 
Fig. 4 Hypothetical glycosylation of UPIIIa. UPIIIa is highly glycosylated and possess complex N-glycans (blue circles). Bovine UPIII N-glycans may contain Sia linked to Gal via $\alpha(2-3)$ - or $\alpha(2-6)$-glycosidic bonds. Cellular signaling occurs via phosphorylation of the UPIIIa cytoplasmic tail. Drown based on [9] and [58]

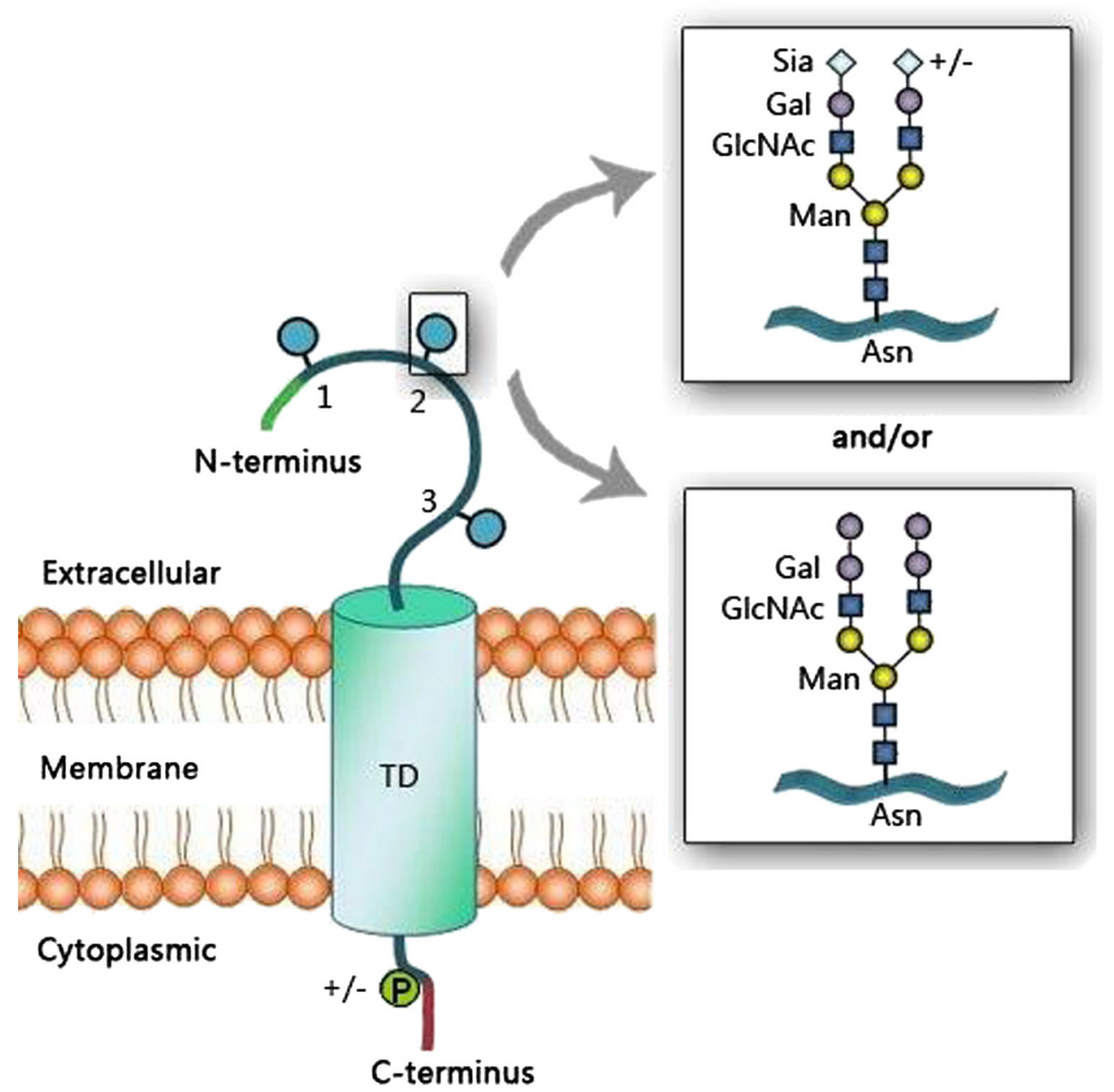

galactose residue $\alpha(1-3)$-linked to the Gal $\beta(1-4)-G l c N A c$ unit of antennary N-glycan (Fig. 4). The occurrence of the Gal $\alpha(1-$ 3)-Gal epitope on N-glycans in UPIII is species specific and such epitope is absent on UPIII and other human N-glycoproteins. Enzyme $\alpha 1,3$-galactosyltransferase is not expressed in humans, apes and Old-World monkeys where the gene is inactivated through frame shift and nonsense mutations [58].

$\mathrm{Hu}$ et al., [6] reported that the UPIII ablation leads to the overexpression, defective glycosylation, and abnormal targeting of UPIb. Interestingly, also UPII ablation leads to a similar up-regulation of the UPIb mRNA level and its hypoglycosylation suggesting that UPIb changes represent a general response to a perturbed uroplakin assembly [13]. The UPIII-depleted urothelium features small plaques, becomes leaky, and has enlarged uretheral orifices resulting in the back flow of urine, hydronephrosis, and altered renal function indicators. Deng et al., [50] reported that in the cases of UPIII ablation, UPI is able to form a dimer with a novel $35-\mathrm{kDa}$ urothelial plaque associated glycoprotein (p35) that is closely related to UPIII [50]. The synthesis of UPIII-related glycoprotein is most likely up-regulated as a compensatory mechanism in the case of UPIII absence. The UPIII-related glycoprotein and UPIII have a similar overall type 1 transmembrane topology. Their amino acid sequences are $34 \%$ identical, share an extracellular juxtamembrane stretch of 19 amino acids and the both UPIII isoforms form a heterodimer with uroplakin Ib, but not with any other UPs. Deng et al., [50] devided p35 UP into uroplakin IIIa (47-49-kDa) and IIIb (35-kDa). In spite of fairly low levels of UPIIIb (10\% of UPIIIa), its interaction with UPIb in ER is believed to be an important early step in urothelial plaque assembly [50]. It has been found that UPIIIb is expressed in urothelial tumors of the urinary bladder in cows that had suffered from chronic enzootic hematuria for several years [59]. Given the fact that the protein parts of the UPIIIa and IIIb have similar molecular masses (approximately $30-\mathrm{kDa}$ ), both isoforms of UPIII can differ in the content of glycosylated and/or phosphorylated residues attached [50].

Recent work by DeSalle'a et al. [60] concerning the divergent evolution of uroplakin, indicated the existence of additional mammalian isoform - UPIIIc. According to the authors, the UPIIIc amino acid sequence is $37 \%$ identical to a protein part of UPIIIb and like two other UPIII isoforms can form heterodimers with UPIb. In contrast to other UPIIIs, UPIIIc isoform does not have a $\sim 20$ aa region between the 
transmembrane domain and the $\mathrm{N}$-terminus of the protein [60]. So far, nothing is known about glycan moiety structure of UPIII isoforms other than UPIIIa.

\section{Mannose residues on UPIa are pivotal for urinary tract E.coli infection}

Urinary tract infection involving $E$. coli constitutes $90 \%$ of all infections of this system and the second most common in the human population infectious disease with high treatment costs $[53,61,62]$. Infection is initiated by attaching bacteria to the normally sterile uroepithelium via a lectin- type 1-fimbriae (FimH) adhesins of E.coli to urothelial surface receptor UPIa, rich in mannose residues $[14,63,64]$. The reaction is specific for $E$. coli expressing adhesins $\mathrm{H}$-type, and not $E$. coli with other types of adhesins or bacteria lacking fimbria [42, 65]. Effective interaction of FimH with UPIa may also cause infections of the upper part of the urinary tract including kidneys since expression of UPIa has been also found in the ureters and renal pelvis [66-68]. In these locations a significant role in bacterial adhesion is attributed to fimbriae $\mathrm{P}$ expressed by certain strains of $E$. coli causing pyelonephritis [69]. Malagolini et al. [58] reported that initiation of infection in cows is also possible via E. coli strains expressing S-type fimbriae able to recognize $\alpha$ (2-3)-sialylated glycans expressed by bovine $\alpha 2,3$-sialylated UPIII glycovariant. After successful invasion, uropathogenic bacteria replicate, invade neighbouring cells, and mature into dense, biofilm-like inclusions. Within the bladder epithelium bacteria can survive for months and are responsible for treatment- challenging recurrent urinary tract infections $[53,63,64]$.

Group of Wu et al. [45] for the first time showed that type 1-fimbriated $E$. coli binds to bovine urothelial plaque proteins via UPIa. Later, in view of significant differences in the glycosylation between UPIa (high mannosylated glycan) and UPIb (almost exclusively complex-type glycan), the former one has been recognized as responsible for $E$. coli infections $[14,42,70,71]$. The multimannosylated glycoforms of UPIb present in minute quantities are buried deeply in the structural pocket and are not available for bacterial adhesins [42].

The urothelial receptor on UPIa for bacterial adhesin FimH was localized by Min et al. [71] on the six inner domains of the $16 \mathrm{~nm}$ urothelial plaque particle. FimH adhesin has a mannosebinding pocket that is capable at $\mathrm{pH} 4-9$ of specific reaction with glycoproteins with exposed mannose residues [14, 70, 71]. FimH binding with UPIa occurs with a moderate strength ( $\mathrm{Kd} \sim 100 \mathrm{nM}$ ), but a multiple binding sites present on the bacteria and multiple array of polymerized UPs receptors, makes the attachment relatively strong [14]. Wellens et al., [63] reported that FimH interacts with $\operatorname{Man} \alpha(1-3) \operatorname{Man} \beta(1-$ 4)GlcNAc $\beta(1-4)$ GlcNAc in an extended binding site. The interactions along the $\alpha(1-3)$ glycosidic bond and the first $\beta(1-4)$ linkage to the chitobiose unit are conserved with those of FimH with buty $\alpha$-D-mannose. The strong stacking of the central mannose with the aromatic ring of Tyr48 is congruent with the high affinity found for synthetic inhibitors in which mannose is substituted by an aromatic group [63].

The adhesion of uropathogenic E. coli to highly mannosylated UPIa is only an initial step of subsequent events in the pathogenesis of urinary tract infections $[64,72,73]$. Studies of Wang et al., [64] indicated that the interaction of lectin-mediated adhesion with the urothelial UPIa can further induce cellular signaling by phosphorylation of the UPIIIa cytoplasmic tail and leads to cytoskeletal rearrangements and further bacterial invasion. They showed by cryo-electron microscopy that FimH binding to the extracellular domain of UPIa induces global conformational changes and movements in all UPs transmembrane helices. Downstream signaling events can be initiated by lateral translocation of the UP cytoplasmic tails [64]. Thumbikat et al. [73] further discovered that equally important to efficient insult by $E$. coli and bacterial adhesion is the UPIIIa cytoplasmic tail phosphorylation on a specific threonine residue by casein kinase II, followed by an elevation of intracellular calcium. Moreover, the same group [72] utilizing in vitro models of urothelial differentiation, demonstrated that $E$. coli mediated cell-death is entirely dependent on the proper differentiation of UPIII and directly correlated with its enhanced maturation. Thus, during the urinary tract infections where superficial urothelial cells are damaged and less differentiated cells are exposed, urothelial apoptosis is reduced [72]. Further, Klumpp et al. [74] using a murine model of urinary tract infection showed that urothelial apoptosis is a key event in the pathogenesis mediated by E.coli and requires both caspase-dependent direct induction of the extrinsic pathway and caspase 8-mediated Bid cleavage -dependent indirect intrinsic pathway [74].

Against excessive colonization by microorganisms, AUM is protected by glycocalyx formed of glycosylated UPs $[5,10$, 75]. Experimental work by Geerlings et al. [76] showed that people with diabetes are more prone to urinary tract infections compared to healthy people. It is therefore suggested that disorders in glycosylation of UPs found for example in diabetes, may have a significant role in the development of urinary tract infections, especially in their recurrent and persistent form $[15,77]$. Like diabetes, bacterial adhesion facilitates transportation of immatured mannosylated glycoproteins to the surface [16]. It has been proven that the expression profile of sugar residues expressed by UPs is more important for the epithelial adhesion of microbes than the variations of an individual determinant of bacterial adhesin [78].

Attempts to block interactions between bacterial adhesins and sugars exposed by UPs are of great importance for unraveling the extremely important clinical issue related to bacterial infections of urothelium. It should be noted that the physiological concentrations of naturally occurring mannosylated glycoprotein 
present in urine (Tamm - Horsfall protein) are able to inhibit adhesion of bacteria and serve as a first line of defense against infection [79, 80]. In recent years, many new revolutionary antibacterial agents that effectively eliminate urinary tract infection have been designed. A particularly promising class of drugs include remedies that inhibit bacterial adhesion to urothelial cells i.e. FimH antagonists for example in the form of vaccines, which, by their mechanism of action minimize bacterial drug resistance [81-84]. Design of FimH antagonists, precisely glycoagonists are based on the imitation of natural sugar epitope structures [63, 83, 85]. Recently, Schwardt et al. [51] attempted to create new FimH antagonists on the structure of triazoles with mannose residues. In other work, in vitro and in vivo studies showed that a protein D present on the surface of the mucous membranes of various organs for example in lungs, has the ability to bind directly to UPIa and block bacterial adhesion to the urothelium [86]. Preventing and treating of urinary tract infections is one of the most important priority of modern medicine because of the universality and continuous increase in the incidence of this medical condition.

\section{Impairment of the mucosal glycoconjugates in IC}

An impairment of the mucosal glycoconjugates could be an important factor in the development of bladder disorders such as interstitial cystitis (IC). The disease is characterized by increased permeability of urothelial membrane, influx of urine into underlining tissues, lower back pain and frequent, urgent and painful voidings [29]. Epidemiological studies indicate that this disease is much more common than recognized clinically. A number of theories have been created to explain the etiology of IC and the data cited by various authors are sometimes contradictory $[87,88]$. One of the most important and most popular theories proposed by Parsons is the concept of increased permeability of the urothelium to harmful substances in the urine that are linked to quantitative and qualitative changes in the layer of GAGs [89]. Parsons et al. showed reduced secretion of GAGs and one of their metabolite uronic acid in urine of IC patients as compared to control group [90]. The observations made using a scanning electron microscope confirmed the reduction in the GAG layer and leakage of urothelial membrane. The concept of increased permeability of urothelial cells was further supported by findings of Fowler et al., which revealed in patients the presence of Tamm-Horsfall protein deposits [91]. Later, Neal et al. established the presence of antibodies against TammHorsfall protein in the patient serum [92]. The majority of patients demonstrated qualitative changes of proteoglycans [88]. These findings again underline a crucial role for the proper composition of glycovariants and precise glycosylation of the urothelium in the function and physiological condition of the urothelial tract.

\section{Glycosylation changes in urothelial cancer}

Cancer derived from the urothelium is the sixth most common type of cancer in the world. About 90-95\% of cases occur in the bladder, the remaining involve the ureter and renal collecting system (about 5-10 \%). In cancer, the cancerassociated carbohydrate structures are reported to play key roles in cancer progression by altering the cell-cell and cellenvironment interactions. As a consequence of neoplastic transformation the cell membrane glycoconjugates undergo characteristic changes [93, 94]. UPs create attractive urothelium tumor markers due to the high conservation of their structure and selective tissue specificity. However, it seems somewhat paradoxical that their expression does not exactly correlate with the degree of differentiation of cancer and they might be found even in metastatic tumors despite the fact that they are final differentiation products of normal urothelial cells $[49,95]$. On the other hand, exploration of the differentiation-dependent glycosylation of uroplakins might shed the light on this conundrum.

So far little is known how glycosylation changes correlate with dedifferentiation of cancer cells, the stage and progression of the disease [16]. Pode et al. [96] showed that expression of Lewis X glycoantygen detected on the umbrella cells is associated with bladder cancer with specificity of $86.4 \%$. The tumor-associated carbohydrate, an antigen sialyl-Tn (STn) and its major biosynthetic enzyme, the sialyltransferase (sT6), highly expressed by several human carcinomas and preneoplastic lesions [93] have been reported to be expressed by tumors of the bladder [97, 98]. Ferreira et al. [97] showed that $75 \%$ of the high-grade bladder tumours, presenting elevated proliferation rates and high risk of recurrence/progression, expressed STn glycotope. The antigen STn has not been found in the normal urothelium, but was mainly expressed in non-proliferative areas of the tumour invading the basal and muscle layers as well in tumour-adjacent mucosa suggesting a tumor field effect. Furthermore, the data of Lima et al. [98] strongly suggested that Bacillus Calmette-Guerin (BCG) immunotherapy is efficient against STn - and s6Tpositive tumours. Further authors proposed that expressions of that glycoantigen and its related enzyme may be used as independent predictive markers of BCG treatment response and in the identification of patients who could benefit from this immunotherapy. Recently, Zupančič et al. demonstrated in rodents a modified expression of speciesdependent sugar moieties during carcinogenesis [16]. Using lectin-immunohistochemical analysis they showed in vivo and ex vivo that rodent neoplastic urothelium displayed higher reactivity with Jacalin (lectin from Artocarpus integrifolia) as compared to normal tissue. Unlike in mouse carcinogenesis model, in rat model the decreased binding to another natural Amaranthus caudatus lectin was noted. Moreover, in normal urothelium, terminally differentiated 
umbrella cells expressed all four UPs, which were present in the large urothelial plaques covering mature fusiform vesicles and the apical plasma membrane. In contrast, the preneoplastic urothelium contained poorly differentiated cells with microvilli and small, round vesicles that were uroplakin-negative and no urothelial plaques were observed in these cells [16].

UPII and particularly UPIII are considered as highly tissue-specific and moderately sensitive markers for primary and metastatic urothelial cancers, metastatic cancer of unknown primary origin, and markers that differentiate primary carcinoma of the urothelium from other cancers of the genitourinary system $[5,10,59$, 99-110]. UPIII is also considered as valuable and sensitive marker appearing in urine in association with bladder cancer [108]. However, none of the research team analyzed the alterations in the expression/s of glycotope/s on UPs in relation to cancer of the bladder and/or urinary tract. Future studies and insight into UP glycoforms as differential diagnostic and early indicators of urotelial cancer should be encouraged.

Besides the diagnostic usage for glycovariants of UPs, studies of their glycoconjugates carry important applications in the future for development of targeted drugs through lectins. A specific structure of oligosaccharide moieties of the urothelium glycoconjugates has been tested for improved intravesical drug delivery in cancer therapy [111, 112]. The idea of glycotargets approach of Neutsch et al. [111, 112] is based on a molecular efficient cytoinvasion of uropathogenic bacteria, mediated via a mannose-directed FimH adhesin, and malignancy-dependent differences in bladder cell glycosylation. Their carrier-based delivery concept, combines biorecognitive targeting using plant lectin wheat germ agglutinin (WGA) immobilized on poly(lactide-coglycolide) microparticles for steady cytoadhesion. Several DNA-selective chemotherapeutics with established track record in uro-oncology for physicochemical compatibility with the polymeric carrier formulation have been tested and the preliminary data are promising. The results of this work show potential in glycotargeted deliveries in the intravesical setting and offer new perspectives for the application of lectin-based drugs in the urinary tract malfunctions [112]. However, progress on drug delivery systems tailored to the penetration-hostile urothelial barrier lags behind the advancements in comparable fields.

\section{Conclusions and future prospects}

Particularly fascinating and newly discovered aspect of uroplakin biology and thus the biology and physiology of the urothelium are uroplakin glycovariants. It seems that an in-depth knowledge of the molecular pathogenesis of glycosylation, formation of microheterogenic glycoforms, products of their metabolism and degradation may set new directions for future research. Some of glycotopes terminated by sialic acid and/or fucose as tumor markers could potentially be used to detect tumors in asymptomatic patients, especially at high risk or monitoring of recurrence after treatment of the primary tumor.

Besides of diagnostic usage, the glycoconjugates can carry important applications in lectin-mediated drug delivery [16]. Blood- urine barrier which forms the urothelium is one of the least permeable membranes of the body and is also a challenge to the penetration of drugs. Studies by Kreft et al. showed that the WGA lectin binds to and is endocytosed by umbrella cells at hinge regions, a potential entry for biopharmaceuticals $[113,114]$. The use of lectins recognizing the sugar residues at this particular region can be very effective and valuable in construction of targeted therapies and the treatment of infectious diseases, cancer and IC of the urinary system. Such selective delivery of the active ingredient (drug) directly to urothelium allows targeted treatment without creation of aberrant cell damage to healthy tissues.

There is no doubt that glycosylation of UPs is closely related to UPs function and its malfunction is a reflection of the ongoing pathological process. Due to the fact that changes in the glycosylation of UPs are primary to the underlying changes in relation to the overall expression of the UP, their early detection may help to capture lesions in their early stages. Since urine analysis has a number of advantages, including the availability of large quantities of the material and noninvasive sampling, testing glycobiomarkers in urine is highly desirable [115]. In order to evaluate and validate the clinical utility of UPs glycoforms, their variable molecular native forms and/or possibly degraded, mannosylated versus sialylated and fucosylated glycovariants, further studies on the large scale and the involvement of multidisciplinary research teams are needed.

Conflict of interest The authors declare that there is no conflict of interest.

Open Access This article is distributed under the terms of the Creative Commons Attribution License which permits any use, distribution, and reproduction in any medium, provided the original author(s) and the source are credited.

\section{References}

1. Deng, F.M., Ding, M., Lavker, R.M., Sun, T.T.: Urothelial function reconsidered: a new role in urinary protein secretion. Urology $\mathbf{5 7}$, 117 (2001)

2. Apodaca, G.: The uroepithelium: not just a passive barrier. Traffic 5, $117-128$ (2004) 
3. Khandelwal, P., Abraham, S.N., Apodaca, G.: Cell biology and physiology of the uroepithelium. Am J Physiol Renal Physiol 297, F1477-1501 (2009)

4. Yu, W., Hill, W.G.: Defining protein expression in the urothelium: a problem of more than transitional interest. Am J Physiol Renal Physiol 301, F932-F942 (2011)

5. Wu, X.R., Kong, X., Pellicer, A., Kreibich, G., Sun, T.T.: Uroplakins in urothelial biology, function, and disease. Kidney Int 75, 1153-1165 (2009)

6. Hu, P., Deng, F.M., Liang, F.X., Hu, C.M., Auerbach, A.B..., Shapiro, E., Wu, X.R., Kachar, B., Sun, T.T.: Ablation of uroplakin III gene results in small urothelial plaques, urothelial leakage, and vesicoureteral reflux. J Cell Biol 151, 961-972 (2000)

7. Kreplak, L., Wang, H., Aebi, U., Kong, X.P.: Atomic force microscopy of mammalian urothelial surface. J Mol Biol 374, 365-373 (2007)

8. Wu, X.R., Medina, J.J., Sun, T.T.: Selective interactions of UPIa and UPIb, two members of the transmembrane 4 superfamily, with distinct single transmembrane-domained proteins in differentiated urothelial cells. J Biol Chem 270, 29752-29759 (1995)

9. Wu, X.R., Sun, T.T.: Molecular cloning of a $47 \mathrm{kDa}$ tissue-specific and differentiation-dependent urothelial cell surface glycoprotein. J Cell Sci 106, 31-43 (1993)

10. Jenkins, D., Woolf, A.S.: Uroplakins: new molecular players in the biology of urinary tract malformations. Kidney Int 71, 195-200 (2007)

11. Lee, G.: Uroplakins in the lower urinary tract. Int Neurourol J 15, 4 $12(2011)$

12. Chopra, B., Hinley, J., Oleksiewicz, M.B., Southgate, J.: Transspecies comparison of PPAR and RXR expression by rat and human urothelial tissues. Toxicol Pathol 36, 485-495 (2008)

13. Kong, X.T., Deng, F.M., Hu, P., Liang, F.X., Zhou, G., Auerbach, A.B..., Genieser, N., Nelson, P.K., Robbins, E.S., Shapiro, E., Kachar, B., Sun, T.T.: Roles of uroplakins in plaque formation, umbrella cell enlargement, and urinary tract diseases. J Cell Biol 167, 1195-1204 (2004)

14. Zhou, G., Mo, W.J., Sebbel, P., Min, G., Neubert, T.A., Glockshuber, R., Wu, X.R., Sun, T.T., Kong, X.P.: Uroplakin Ia is the urothelial receptor for uropathogenic Escherichia coli: evidence from in vitro FimH binding. J Cell Sci 114, 4095-4103 (2001)

15. Taganna, J., de Boer, A.R., Wuhrer, M., Bouckaert, J.: Glycosylation changes as important factors for the susceptibility to urinary tract infection. Biochem Soc Trans 39, 349-354 (2011)

16. Zupančič, D., Kreft, M.E., Romih, R.: Selective binding of lectins to normal and neoplastic urothelium in rat and mouse bladder carcinogenesis models. Protoplasma 251, 49-59 (2014)

17. García-España, A., Chung, P.J., Zhao, X., Lee, A., Pellicer, A., Yu, J., Sun, T.T., Desalle, R.: Origin of the tetraspanin uroplakins and their co-evolution with associated proteins: implications for uroplakin structure and function. Mol Phylogenet Evol 41, 355-367 (2006)

18. Min, G., Wang, H., Sun, T.T., Kong, X.P.: Structural basis for tetraspanin functions as revealed by the cryo-EM structure of uroplakin complexes at 6-A resolution. J Cell Biol 173, 975-983 (2006)

19. Romanska, H.M., Berditchevski, F.: Tetraspanins in human epithelial malignancies. J Pathol 223, 4-14 (2011)

20. Lin, J.H., Wu, X.R., Kreibich, G., Sun, T.T.: Precursor sequence, processing, and urothelium-specific expression of a major $15-\mathrm{kDa}$ protein subunit of asymmetric unit membrane. J Biol Chem 269, 1775-1784 (1994)

21. Tu, L., Kong, X.P., Sun, T.T., Kreibich, G.: Integrity of all four transmembrane domains of the tetraspanin uroplakin Ib is required for its exit from the ER. J Cell Sci 119, 5077-5086 (2006)

22. Hu, C.C., Liang, F.X., Zhou, G., Tu, L., Tang, C.H., Zhou, J., Kreibich, G., Sun, T.T.: Assembly of urothelial plaques: tetraspanin function in membrane protein trafficking. Mol Biol Cell 16, $3937-$ $3950(2005)$

23. Liang, F.X., Riedel, I., Deng, F.M., Zhou, G., Xu, C., Wu, X.R., Kong, X.P., Moll, R., Sun, T.T.: Organization of uroplakin subunits: transmembrane topology, pair formation and plaque composition. Biochem J 355, 13-18 (2001)

24. Tu, L., Sun, T.T., Kreibich, G.: Specific heterodimer formation is a prerequisite for uroplakins to exit from the endoplasmic reticulum. Mol Biol Cell 13, 4221-4230 (2002)

25. Hu, P., Meyers, S., Liang, F.X., Deng, F.M., Kachar, B., Zeidel, M.L., Sun, T.T.: Role of membrane proteins in permeability barrier function: uroplakin ablation elevates urothelial permeability. Am J Physiol Renal Physiol 283, F1200-1207 (2002)

26. Rodriguez-Boulan, E., Kreitzer, G., Müsch, A.: Organization of vesicular trafficking in epithelia. Nat Rev Mol Cell Biol 6, 233247 (2005)

27. Mellman, I., Nelson, W.J.: Coordinated protein sorting, targeting and distribution in polarized cells. Nat Rev Mol Cell Biol 9, 833845 (2008)

28. Kachar, B., Liang, F., Lins, U., Ding, M., Wu, X.R., Stoffler, D., Aebi, U., Sun, T.T.: Three-dimensional analysis of the $16 \mathrm{~nm}$ urothelial plaque particle: luminal surface exposure, preferential head-to-head interaction, and hinge formation. J Mol Biol 285, 595-608 (1999)

29. Lewis, S.A.: Everything you wanted to know about the bladder epithelium but were afraid to ask. Am J Physiol Renal Physiol 278, F867-874 (2000)

30. Zhou, G., Liang, F.X., Romih, R., Wang, Z., Liao, Y., Ghiso, J., Luque-Garcia, J.L., Neubert, T.A., Kreibich, G., Alonso, M.A., Schaeren-Wiemers, N., Sun, T.T.: MAL facilitates the incorporation of exocytic uroplakin-delivering vesicles into the apical membrane of urothelial umbrella cells. Mol Biol Cell 23, 1354-1366 (2012)

31. Folsch, H., Mattila, P.E., Weisz, O.A.: Taking the scenic route: biosynthetic traffic to the plasma membrane in polarized epithelial cells. Traffic 10, 972-981 (2009)

32. Carmosino, M., Valenti, G., Caplan, M., Svelto, M.: Polarized traffic towards the cell surface: how to find the route. Biol Cell 102, 75-91 (2009)

33. Adachi, W., Okubo, K., Kinoshita, S.: Human uroplakin Ib in ocular surface epithelium. Invest Ophthalmol Vis Sci 41, 2900 2905 (2000)

34. Buckley, M., Xin, P., Washington, S., Herb, N., Erickson, D., Bhavanandan, V.P.: Lectin histochemical examination of rabbit bladder glycoproteins and characterization of a mucin isolated from the bladder mucosa. Arch Biochem Biophys 375, 270-277 (2000)

35. Vinter-Jensen, L., Ørntoft, T.F.: Glycoproteins in the urothelium and in the urine of the epidermal growth factor induced growing urinary tract in rats. Urol Res 26, 97-103 (1998)

36. Buckley, M.S., Washington, S., Laurent, C., Erickson, D.R., Bhavananadan, V.P.: Characterization and immunohistochemical localization of the glycoconjugates of the rabbit bladder mucosa. Arch Biochem Biophys 330, 163-173 (1996)

37. Bhavanandan, V.P., Zhu, Q., Yamakami, K., Dilulio, N.A., Nair, S., Capon, C., Lemoine, J., Fournet, B.: Purification and characterization of the MUC1 mucin-type glycoprotein, epitectin, from human urine: structures of the major oligosaccharide alditols. Glycoconj $\mathrm{J}$ 15, 37-49 (1998)

38. Higuchi, T., Xin, P., Buckley, M.S., Erickson, D.R., Bhavanandan, V.P.: Characterization of the rabbit homolog of human MUC1 glycoprotein isolated from bladder by affinity chromatography on immobilized jacalin. Glycobiology 10, 659-667 (2000)

39. Desantis, S., Accogli, G., Zizza, S., Arrighi, S.: In situ characterization of glycans in the urothelium of donkey bladder: evidence of secretion of sialomucins. Acta Histochem 115, 712-718 (2013) 
40. N'Dow, J., Jordan, N., Robson, C.N., Neal, D.E., Pearson, J.P.: The bladder does not appear to have a dynamic secreted continuous mucous gel layer. J Urol 173, 2025-2031 (2005)

41. Halim, A., Nilsson, J., Ruetschi, U., Hesse, C., Larson, G.: Human urinary glycoproteomics; attachment site specific analysis of $\mathrm{N}$ - and O-linked glycosylations by CID and ECD. Mol Cell Proteomics 11, M111 (2012)

42. Xie, B., Zhou, G., Chan, S.Y., Shapiro, E., Kong, X.P., Wu, X.R., Sun, T.T., Costello, C.E.: Distinct glycan structures of uroplakins Ia and Ib: structural basis for the selective binding of FimH adhesin to uroplakin Ia. J Biol Chem 281, 14644-14653 (2006)

43. Wu, X., Kakehi, Y., Zeng, Y., Taoka, R., Tsunemori, H., Inui, M.: Uroplakin II as a promising marker for molecular diagnosis of nodal metastases from bladder cancer: comparison with cytokeratin 20 . J Urol 174, 2138-2142 (2005)

44. Kreft, M.E., Hudoklin, S., Jezernik, K., Romih, R.: Formation and maintenance of blood-urine barrier in urothelium. Protoplasma 246, $3-14(2010)$

45. Wu, X.R., Sun, T.T., Medina, J.J.: In vitro binding of type 1fimbriated Escherichia coli to uroplakins Ia and Ib: relation to urinary tract infections. Proc Natl Acad Sci U S A 93, 96309635 (1996)

46. Yu, J., Lin, J.H., Wu, X.R., Sun, T.T.: Uroplakins Ia and Ib, two major differentiation products of bladder epithelium, belong to a family of four transmembrane domain (4TM) proteins. J Cell Biol 125, 171-182 (1994)

47. Yu, J., Manabe, M., Wu, X.R., Xu, C., Surya, B., Sun, T.T.: Uroplakin I: a $27-\mathrm{kD}$ protein associated with the asymmetric unit membrane of mammalian urothelium. J Cell Biol 111, 1207-1216 (1990)

48. Wu, X.R., Lin, J.H., Walz, T., Haner, M., Yu, J., Aebi, U., Sun, T.T.: Mammalian uroplakins. A group of highly conserved urothelial differentiation-related membrane proteins. J Biol Chem 269, 13716-13724 (1994)

49. Huang, H.Y., Shariat, S.F., Sun, T.T., Lepor, H., Shapiro, E., Hsieh, J.T., Ashfaq, R., Lotan, Y., Wu, X.R.: Persistent uroplakin expression in advanced urothelial carcinomas: implications in urothelial tumor progression and clinical outcome. Hum Pathol 38, 1703-1713 (2007)

50. Deng, F.M., Liang, F.X., Tu, L., Resing, K.A., Hu, P., Supino, M., Hu, C.C., Zhou, G., Ding, M., Kreibich, G., Sun, T.T.: Uroplakin IIIb, a urothelial differentiation marker, dimerizes with uroplakin $\mathrm{Ib}$ as an early step of urothelial plaque assembly. J Cell Biol 159, 685-694 (2002)

51. Schwardt, O., Rabbani, S., Hartmann, M., Abgottspon, D., Wittwer, M., Kleeb, S., Zalewski, A., Smiesko, M., Cutting, B., Ernst, B.: Design, synthesis and biological evaluation of mannosyl triazoles as FimH antagonists. Bioorg Med Chem 19, 6454-6473 (2011)

52. Schwarz, F., Aebi, M.: Mechanisms and principles of N-linked protein glycosylation. Curr Opin Struct Biol 21, 576-582 (2011)

53. Anderson, G.G., Dodson, K.W., Hooton, T.M., Hultgren, S.J.: Intracellular bacterial communities of uropathogenic Escherichia coli in urinary tract pathogenesis. Trends Microbiol 12, 424-430 (2004)

54. Sun, T.T.: Altered phenotype of cultured urothelial and other stratified epithelial cells: implications for wound healing. Am J Physiol Renal Physiol 291, F9-21 (2006)

55. Berger, E.G.: Ectopic localizations of Golgi glycosyltransferases. Glycobiology 12, 29R-36R (2002)

56. Nakayama, M., Kawaguchi, Y., Yamada, K., Hasegawa, T., Takazoe, K., Katoh, N., Hayakawa, H., Osaka, N., Yamamoto, H., Ogawa, A., Kubo, H., Shigematsu, T., Sakai, O., Horiuchi, S.: Immunohistochemical detection of advanced glycosylation endproducts in the peritoneum and its possible pathophysiological role in CAPD. Kidney Int 51, 182-186 (1997)
57. Hu, C.C., Bachmann, T., Zhou, G., Liang, F.X., Ghiso, J., Kreibich, G., Sun, T.T.: Assembly of a membrane receptor complex: roles of the uroplakin II prosequence in regulating uroplakin bacterial receptor oligomerization. Biochem J 414, 195-203 (2008)

58. Malagolini, N., Cavallone, D., Wu, X.R., Serafini-Cessi, F.: Terminal glycosylation of bovine uroplakin III, one of the major integral-membrane glycoproteins of mammalian bladder. Biochim Biophys Acta 1475, 231-237 (2000)

59. Roperto, S., Ambrosio, V., Borzacchiello, G., Galati, P., Paciello, O., Russo, V., Roperto, F.: Bovine papillomavirus type-2 (BPV-2) infection and expression of uroplakin IIIb, a novel urothelial cell marker, in urinary bladder tumors of cows. Vet Pathol 42, 812-818 (2005)

60. Desalle, R., Chicote, J.U., Sun, T.T., Garcia-Espana, A.: Generation of divergent uroplakin tetraspanins and their partners during vertebrate evolution: identification of novel uroplakins. BMC Evol Biol 14, 13 (2014)

61. Foxman, B., Brown, P.: Epidemiology of urinary tract infections: transmission and risk factors, incidence, and costs. Infect Dis Clin North Am 17, 227-241 (2003)

62. Litwin, M.S., Saigal, C.S., Yano, E.M., Avila, C., Geschwind, S.A., Hanley, J.M., Joyce, G.F., Madison, R., Pace, J., Polich, S.M., Wang, M.: Urologic diseases in america project: analytical methods and principal findings. J Urol 173, 933-937 (2005)

63. Wellens, A., Garofalo, C., Nguyen, H., Van Gerven, N., Slattegard, R., Hernalsteens, J.P., Wyns, L., Oscarson, S., De Greve, H., Hultgren, S., Bouckaert, J.: Intervening with urinary tract infections using anti-adhesives based on the crystal structure of the FimH-oligomannose- 3 complex. PLoS One 3, e2040 (2008)

64. Wang, H., Min, G., Glockshuber, R., Sun, T.T., Kong, X.P. Uropathogenic E coli adhesin-induced host cell receptor conformational changes: implications in transmembrane signaling transduction. J Mol Biol 392, 352-361 (2009)

65. Schembri, M.A., Kjaergaard, K., Sokurenko, E.V., Klemm, P.: Molecular characterization of the Escherichia coli FimH adhesin. J Infect Dis 183, S28-31 (2001)

66. Jiang, S., Gitlin, J., Deng, F.M., Liang, F.X., Lee, A., Atala, A., Bauer, S.B., Ehrlich, G.D., Feather, S.A., Goldberg, J.D., Goodship, J.A., Goodship, T.H., Hermanns, M., Hu, F.Z., Jones, K.E., Malcolm, S., Mendelsohn, C., Preston, R.A., Retik, A.B..., Schneck, F.X., Wright, V., Ye, X.Y., Woolf, A.S., Wu, X.R., Ostrer, H., Shapiro, E., Yu, J., Sun, T.T.: Lack of major involvement of human uroplakin genes in vesicoureteral reflux: implications for disease heterogeneity. Kidney Int 66, 10-19 (2004)

67. Liang, F.X., Bosland, M.C., Huang, H., Romih, R., Baptiste, S., Deng, F.M., Wu, X.R., Shapiro, E., Sun, T.T.: Cellular basis of urothelial squamous metaplasia: roles of lineage heterogeneity and cell replacement. J Cell Biol 171, 835-844 (2005)

68. Romih, R., Korosec, P., de Mello, W., Jezernik Jr., K.: Differentiation of epithelial cells in the urinary tract. Cell Tissue Res 320, 259-268 (2005)

69. Roberts, J.A., Marklund, B.I., Ilver, D., Haslam, D., Kaack, M.B., Baskin, G., Louis, M., Mollby, R., Winberg, J., Normark, S.: The Gal(alpha 1-4)Gal-specific tip adhesin of Escherichia coli Pfimbriae is needed for pyelonephritis to occur in the normal urinary tract. Proc Natl Acad Sci U S A 91, 11889-11893 (1994)

70. Sokurenko, E.V., Schembri, M.A., Trintchina, E., Kjaergaard, K., Hasty, D.L., Klemm, P.: Valency conversion in the type 1 fimbrial adhesin of Escherichia coli. Mol Microbiol 41, 675-686 (2001)

71. Min, G., Stolz, M., Zhou, G., Liang, F., Sebbel, P., Stoffler, D. Glockshuber, R., Sun, T.T., Aebi, U., Kong, X.P.: Localization of uroplakin Ia, the urothelial receptor for bacterial adhesin FimH, on the six inner domains of the $16 \mathrm{~nm}$ urothelial plaque particle. J Cell Biol 317, 697-706 (2002) 
72. Thumbikat, P., Berry, R.E., Schaeffer, A.J., Klumpp, D.J.: Differentiation-induced uroplakin III expression promotes urothelial cell death in response to uropathogenic E coli. Microbes Infect 11, 57-65 (2009)

73. Thumbikat, P., Berry, R.E., Zhou, G., Billips, B.K., Yaggie, R.E., Zaichuk, T., Sun, T.T., Schaeffer, A.J., Klumpp, D.J.: Bacteriainduced uroplakin signaling mediates bladder response to infection. PLoS Pathog 5, e1000415 (2009)

74. Klumpp, D.J., Rycyk, M.T., Chen, M.C., Thumbikat, P., Sengupta, S., Schaeffer, A.J.: Uropathogenic Escherichia coli induces extrinsic and intrinsic cascades to initiate urothelial apoptosis. Infect Immun 74, 5106-5113 (2006)

75. Hauser, P.J., Dozmorov, M.G., Bane, B.L., Slobodov, G., Culkin, D.J., Hurst, R.E.: Abnormal expression of differentiation related proteins and proteoglycan core proteins in the urothelium of patients with interstitial cystitis. J Urol 179, 764-769 (2008)

76. Geerlings, S.E.: Urinary tract infections in patients with diabetes mellitus: epidemiology, pathogenesis and treatment. Int $\mathrm{J}$ Antimicrob Agents 1, S54-57 (2008)

77. Mulvey, M.A., Lopez-Boado, Y.S., Wilson, C.L., Roth, R., Parks, W.C., Heuser, J., Hultgren, S.J.: Induction and evasion of host defenses by type 1-piliated uropathogenic Escherichia coli. Science 282, 1494-1497 (1998)

78. Bouckaert, J., Mackenzie, J., de Paz, J.L., Chipwaza, B., Choudhury, D., Zavialov, A., Mannerstedt, K., Anderson, J., Pierard, D., Wyns, L., Seeberger, P.H., Oscarson, S., De Greve, H., Knight, S.D.: The affinity of the FimH fimbrial adhesin is receptor-driven and quasi-independent of Escherichia coli pathotypes. Mol Microbiol 61, 1556-1568 (2006)

79. Mo, L., Zhu, X.H., Huang, H.Y., Shapiro, E., Hasty, D.L., Wu, X.R.: Ablation of the Tamm-Horsfall protein gene increases susceptibility of mice to bladder colonization by type 1fimbriated Escherichia coli. Am J Physiol Renal Physiol 286, F795-802 (2004)

80. Pak, J., Pu, Y., Zhang, Z.T., Hasty, D.L., Wu, X.R.: Tamm-Horsfall protein binds to type 1 fimbriated Escherichia coli and prevents E. coli from binding to uroplakin Ia and Ib receptors. J Biol Chem 276, 9924-9930 (2001)

81. Abgottspon, D., Ernst, B.: In vivo evaluation of FimH antagonists a novel class of antimicrobials for the treatment of urinary tract infection. Chimia 66, 166-169 (2012)

82. Bouckaert, J., Berglund, J., Schembri, M., De Genst, E., Cools, L., Wuhrer, M., Hung, C.S., Pinkner, J., Slattegard, R., Zavialov, A., Choudhury, D., Langermann, S., Hultgren, S.J., Wyns, L., Klemm, P., Oscarson, S., Knight, S.D., De Greve, H.: Receptor binding studies disclose a novel class of highaffinity inhibitors of the Escherichia coli FimH adhesin. Mol Microbiol 55, 441-455 (2005)

83. Jiang, X., Abgottspon, D., Kleeb, S., Rabbani, S., Scharenberg, M., Wittwer, M., Haug, M., Schwardt, O., Ernst, B.: Antiadhesion therapy for urinary tract infections-a balanced $\mathrm{PK} / \mathrm{PD}$ profile proved to be key for success. J Med Chem 55, 4700-4713 (2012)

84. Meiland, R., Geerlings, S.E., Langermann, S., Brouwer, E.C., Coenjaerts, F.E., Hoepelman, A.I.: Fimch antiserum inhibits the adherence of Escherichia coli to cells collected by voided urine specimens of diabetic women. J Urol 171, 1589-1593 (2004)

85. Barras, A., Martin, F.A., Bande, O., Baumann, J.S., Ghigo, J.M., Boukherroub, R., Beloin, C., Siriwardena, A., Szunerits, S.: Glycanfunctionalized diamond nanoparticles as potent $E$. coli anti-adhesives. Nanoscale 5, 2307-2316 (2013)

86. Kurimura, Y., Nishitani, C., Ariki, S., Saito, A., Hasegawa, Y., Takahashi, M., Hashimoto, J., Takahashi, S., Tsukamoto, T., Kuroki, Y.: Surfactant protein D inhibits adherence of uropathogenic Escherichia coli to the bladder epithelial cells and the bacterium-induced cytotoxicity: a possible function in urinary tract. J Biol Chem 287, 39578-39588 (2012)
87. Nordling, J., Fall, M., Hanno, P.: Global concepts of bladder pain syndrome (interstitial cystitis). World J Urol 30, 457-464 (2012)

88. Hanno, P.M.: Interstitial cystitis-epidemiology, diagnostic criteria, clinical markers. Rev Urol 4, S3-8 (2002)

89. Akiyama, A., Stein, P.C., Houshiar, A., Parsons, C.L.: Urothelial cytoprotective activity of Tamm-Horsfall protein isolated from the urine of healthy subjects and patients with interstitial cystitis. Int J Urol 7, 176-183 (2000)

90. Parsons, C.L.: Interstitial cystitis: epidemiology and clinical presentation. Clin Obstet Gynecol 45, 242-249 (2002)

91. Fowler Jr., J.E., Lynes, W.L., Lau, J.L., Ghosh, L., Mounzer, A.: Interstitial cystitis is associated with intraurothelial Tamm-Horsfall protein. J Urol 140, 1385-1389 (1988)

92. Neal Jr., D.E., Dilworth, J.P., Kaack, M.B.: Tamm-Horsfall autoantibodies in interstitial cystitis. J Urol 145, 37-39 (1991)

93. Dall'Olio, F., Malagolini, N., Trinchera, M., Chiricolo, M.: Mechanisms of cancer-associated glycosylation changes. Front Biosci (Landmark Ed) 17(670-699) (2012)

94. Hauselmann, I., Borsig, L.: Altered tumor-cell glycosylation promotes metastasis. Front Oncol 4, 28 (2014)

95. Wu, R.L., Osman, I., Wu, X.R., Lu, M.L., Zhang, Z.F., Liang, F.X., Hamza, R., Scher, H., Cordon-Cardo, C., Sun, T.T.: Uroplakin II gene is expressed in transitional cell carcinoma but not in bilharzial bladder squamous cell carcinoma: alternative pathways of bladder epithelial differentiation and tumor formation. Cancer Res 58, 1291-1297 (1998)

96. Pode, D., Golijanin, D., Sherman, Y., Lebensart, P., Shapiro, A.: Immunostaining of Lewis $\mathrm{X}$ in cells from voided urine, cytopathology and ultrasound for noninvasive detection of bladder tumors. J Urol 159, 389-392 (1998)

97. Ferreira, J.A., Videira, P.A., Lima, L., Pereira, S., Silva, M., Carrascal, M., Severino, P.F., Fernandes, E., Almeida, A., Costa, C., Vitorino, R., Amaro, T., Oliveira, M.J., Reis, C.A., Dall'Olio, F., Amado, F., Santos, L.L.: Overexpression of tumour-associated carbohydrate antigen sialyl-Tn in advanced bladder tumours. Mol Oncol 7, 719731 (2013)

98. Lima, L., Severino, P.F., Silva, M., Miranda, A., Tavares, A., Pereira, S., Fernandes, E., Cruz, R., Amaro, T., Reis, C.A., Dall'Olio, F., Amado, F., Videira, P.A., Santos, L., Ferreira, J.A.: Response of high-risk of recurrence/progression bladder tumours expressing sialyl-Tn and sialyl-6-T to BCG immunotherapy. Br J Cancer 109, 2106-2114 (2013)

99. Kaufmann, O., Volmerig, J., Dietel, M.: Uroplakin III is a highly specific and moderately sensitive immunohistochemical marker for primary and metastatic urothelial carcinomas. Am J Clin Pathol 113, 683-687 (2000)

100. Konety, B.R.: Molecular markers in bladder cancer: a critical appraisal. Urol Oncol 24, 326-337 (2006)

101. Lobban, E.D., Smith, B.A., Hall, G.D., Harnden, P., Roberts, P., Selby, P.J., Trejdosiewicz, L.K., Southgate, J.: Uroplakin gene expression by normal and neoplastic human urothelium. Am J Pathol 153, 1957-1967 (1998)

102. Olsburgh, J., Harnden, P., Weeks, R., Smith, B., Joyce, A., Hall, G., Poulsom, R., Selby, P., Southgate, J.: Uroplakin gene expression in normal human tissues and locally advanced bladder cancer. J Pathol 199, 41-49 (2003)

103. Parker, D.C., Folpe, A.L., Bell, J., Oliva, E., Young, R.H., Cohen, C., Amin, M.B.: Potential utility of uroplakin III, thrombomodulin, high molecular weight cytokeratin, and cytokeratin 20 in noninvasive, invasive, and metastatic urothelial (transitional cell) carcinomas. Am J Surg Pathol 27, 1-10 (2003)

104. Chuang, A.Y., DeMarzo, A.M., Veltri, R.W., Sharma, R.B., Bieberich, C.J., Epstein, J.I.: Immunohistochemical differentiation of high-grade prostate carcinoma from urothelial carcinoma. Am J Surg Pathol 31, 1246-1255 (2007) 
105. Copp, H.L., Chin, J.L., Conaway, M., Theodorescu, D.: Prospective evaluation of the prognostic relevance of molecular staging for urothelial carcinoma. Cancer 107, 60-66 (2006)

106. Gruver, A.M., Amin, M.B., Luthringer, D.J., Westfall, D., Arora, K., Farver, C.F., Osunkoya, A.O., McKenney, J.K., Hansel, D.E.: Selective immunohistochemical markers to distinguish between metastatic high-grade urothelial carcinoma and primary poorly differentiated invasive squamous cell carcinoma of the lung. Arch Pathol Lab Med 136, 13391346 (2012)

107. Gulmann, C., Paner, G.P., Parakh, R.S., Hansel, D.E., Shen, S.S., Ro, J.Y., Annaiah, C., Lopez-Beltran, A., Rao, P., Arora, K., Cho, Y., Herrera-Hernandez, L., Alsabeh, R., Amin, M.B.: Immunohistochemical profile to distinguish urothelial from squamous differentiation in carcinomas of urothelial tract. Hum Pathol 44, 164-172 (2013)

108. Lai, Y., Ye, J., Chen, J., Zhang, L., Wasi, L., He, Z., Zhou, L., Li, H., Yan, Q., Gui, Y., Cai, Z., Wang, X., Guan, Z.: UPK3A: a promising novel urinary marker for the detection of bladder cancer. Urology 76, e6-11 (2010)

109. Matsumoto, K., Satoh, T., Irie, A., Ishii, J., Kuwao, S., Iwamura, M., Baba, S.: Loss expression of uroplakin III is associated with clinicopathologic features of aggressive bladder cancer. Urology $\mathbf{7 2}$, 444-449 (2008)
110. Smith, S.C., Mohanty, S.K., Kunju, L.P., Chang, E., Chung, F., Carvalho, J.C., Paner, G.P., Hansel, D.E., Luthringer, D.J., Deperalta-Ventrurina, M.N., Amin, M.B.: Uroplakin II outperforms uroplakin III in diagnostically challenging settings. Histopathology 65, 132-138 (2014)

111. Neutsch, L., Eggenreich, B., Herwig, E., MarchettiDeschmann, M., Allmaier, G., Gabor, F., Wirth, M.: Lectin bioconjugates trigger urothelial cytoinvasion-a glycotargeted approach for improved intravesical drug delivery. Eur J Pharm Biopharm 82, 367-375 (2012)

112. Neutsch, L., Wambacher, M., Wirth, E.M., Spijker, S., Kahlig, H., Wirth, M., Gabor, F.: UPEC biomimickry at the urothelial barrier: lectin-functionalized PLGA microparticles for improved intravesical chemotherapy. Int $\mathrm{J}$ Pharm 450, 163-176 (2013)

113. Kreft, M.E., Jezernik, K., Kreft, M., Romih, R.: Apical plasma membrane traffic in superficial cells of bladder urothelium. Ann N Y Acad Sci 1152, 18-29 (2009)

114. Kreft, M.E., Romih, R., Kreft, M., Jezernik, K.: Endocytotic activity of bladder superficial urothelial cells is inversely related to their differentiation stage. Differentiation 77,48 59 (2009)

115. Husi, H., Fearon, K.C., Ross, J.A.: Can a simple proteomics urine test assist in the early diagnosis of early-stage cancer? Expert Rev Proteomics 8, 555-557 (2011) 